\title{
O CUSTO ALUNO DA EDUCAÇÃO INFANTIL DE TERESINA: ENTRE A REALIDADE DO FUNDEB E O SONHO DO CAQi
}

\author{
Luis Carlos Sales" \\ Universidade Federal do Piauí (UFPI) \\ Antonia Melo de Sousa*" \\ Universidade Federal do Piauí (UFPI)
}

RESUMO: Por que a União precisa aportar mais recursos para a área de educação? Este artigo faz uma contextualização da política educacional brasileira, enfatizando as políticas de fundo (Fundef e Fundeb); apresenta histórico do processo de municipalização e o estudo do custo aluno/ano da Educação Infantil em Teresina, em 2012. Por meio do método de ingredientes, calculouse o custo aluno/ano, estabelecendo-se um plano de coleta e envolvendo seis categorias relacionadas aos custos diretos de funcionamento das pré-escolas. Constatou-se que o custo da Educação Infantil do município de Teresina ficou acima do valor Fundeb e abaixo do valor projetado para o CAQi e que as receitas do município (próprias e do Fundeb) não são suficientes para atender à demanda da Educação Infantil com a qualidade que a população há tantos anos reclama, o que o Fundef durante dez anos negligenciou, e que o Fundeb ainda não a financia plenamente.

Palavras-chave: Financiamento da Educação. Educação Infantil. CAQi. Fundeb.

http://dx.doi.org/10.1590/0102-4698141253

"Doutor em Educação pela Universidade Federal do Rio Grande do Norte. Professor titular da Universidade Federal do Piauí (UFPI). Pesquisador do Programa de Pós-Graduação em Educação e Vice-Coordenador do Núcleo de Estudos e Pesquisa em Políticas e Gestão da Educação (NUPPEGE/UFPI). E-mail: Ivis2006@gmail.com.

" Mestra em Educação pela Universidade Federal do Piauí. Pedagoga da Rede Pública Municipal de Ensino de Teresina, Piauí. E-mail: antoniamelo@gmail.com. 


\title{
STUDENT COST IN CHILDHOOD EDUCATION IN TERESINA: BETWEEN FUNDEB'S REALITY AND CAQI'S DREAM
}

\begin{abstract}
Why does Brazilian Federal Union needs to invest more resources in education? This article shows a contextualization of Brazilian educational policy, emphasizing the political background (Fundef and Fundeb). It begins with the brief history of the municipalization process and then it shows the expenses student / year of early childhood education in Teresina in 2012. By the ingredients method, cost per student/year was calculated, setting a collection plan involving six categories related to the direct preschools' operation cost. It was perceived, as result, that the cost of early childhood education in Teresina was more than the Fundeb funding and lower than projected for the CAQi Municipality revenue (its own resources and Fundeb) are not enough to fulfill the demand of early childhood education with the quality that people deserve and ask for a long time. This was neglected by Fundef during 10 years and is still not fully financed by Fundeb nowadays.
\end{abstract}

Keywords: Education Financing. Childhood Education. CAQi. Fundeb.

\section{INTRODUÇÃO}

Nas conferências nacionais de educação, a discussão sobre financiamento da educação tem sido bastante acalorada. "10\% do PIB já!" é a palavra de ordem, ou seja, é a frase que sintetiza o conflito que vive o Congresso Nacional e que explica os motivos do atraso e da não aprovação do Plano Nacional de Educação (PNE - Projeto de Lei - PL $n^{\circ}$ 8035/2010), em mais de três anos de discussão no Poder Legislativo'.

Neste contexto, uma pergunta precisa ser respondida: "Por que a União precisa aportar mais recursos para a área de educação?”. Antes de responder a essa pergunta, é preciso revisitar o passado para constatar que a luta por mais recursos para a educação é antiga. Os embates travados não se limitam ao contexto da elaboração do PNE 2001-2010 (Lei 10.172/2001), nem ao contexto da Conferência Nacional de Educação (Conae 2010), tampouco à Conae 2014; os embates têm início muito antes da criação das aulas régias, as quais marcam o surgimento do ensino público oficial e laico, nos tempos do Brasil Colônia. Nesse período, a insuficiência de recursos para a educação tinha nome: subsídio literário. Tal subsídio referia-se a um tributo português, instituído no Brasil após a expulsão dos Jesuítas, que incidia sobre a venda de vinho, vinagre e aguardente (a popular cachaça). O pequeno montante de recurso que era arrecado dá uma ideia da dimensão da escassez de recursos e do seu impacto na qualidade da educação pública brasileira. A vinculação de recursos 
provenientes de imposto, proposta no Manifesto dos Pioneiros da Educação Nova, representou um grande avanço materializado na Constituição de 1934. Recuado na Constituição de 1937, retornou na Carta de 1946, ampliando a participação dos municípios para 20\% da renda resultante dos impostos na manutenção e no desenvolvimento do ensino ${ }^{2}$. Nas últimas décadas, os recursos subvinculados do Fundo de Manutenção e Desenvolvimento do Ensino Fundamental e de Valorização do Magistério (Fundef, 1996 - 2006) e do Fundo de Manutenção e Desenvolvimento da Educação Básica de Valorização dos Profissionais da Educação (Fundeb, desde 2007), não têm sido suficientes para implementar uma educação pública de qualidade, especialmente nos municípios mais pobres do país, ou seja, com menor receita tributária e que dependem da complementação da União.

O principal embate presente na Conae 2010, nas Préconferências 2013 e no Congresso Nacional, em torno das discussões da PL 8035/2010, tem sido os 10\% do PIB (Produto Interno Bruto) para a educação, percentual que pode viabilizar a implementação do Custo Aluno Qualidade Inicial (CAQi), que deveria servir de referência para que a União, no início de cada ano, fixasse e anunciasse um valor mínimo nacional por aluno/ano do Fundeb que correspondesse às necessidades dos estados, Distrito Federal e dos municípios. $\mathrm{O}$ referido valor, ao longo dos anos, não tem sido suficiente para cobrir as despesas com educação e tem ficado bem distante do necessário para se garantir uma oferta de educação pública de qualidade, especialmente nos estados de menor arrecadação tributária.

Com vistas a analisar o valor mínimo nacional por aluno/ ano e a capacidade desse valor de garantir os recursos necessários para se implementar uma educação pública de qualidade, são analisados, neste artigo, os resultados de uma pesquisa que calcula o custo aluno/ano, tomando a Educação Infantil, por meio dos Centros Municipais de Educação Infantil de Teresina (CMEIs), como a etapa da Educação Básica.

$\mathrm{Na}$ metodologia, foram considerados os principais insumos de custos dos CMEIs e alguns aspectos da administração da Secretaria, órgão gestor da Rede Pública Municipal de Ensino de Teresina, não sendo considerados os custos de implantação do imóvel. A principal categoria de custo, profissionais da educação, representou quase $80 \%$ do custo total dos CMEIs. As informações foram coletadas nas Secretarias Municipais de Administração e Secretaria Municipal de Educação, em planilhas eletrônicas, contendo a relação nominal de 936 servidores efetivos lotados nos CMEIs no ano de 2012, bem como dos servidores não efetivos, terceirizados e estagiários. O item 
"O custo aluno/ano da educação infantil de Teresina" apresenta mais informações sobre a metodologia utilizada na pesquisa.

A seguir são apresentadas, à luz da legislação educacional brasileira, as determinações legais que fixaram prazo para que o valor anual por aluno, definido nacionalmente, correspondesse a "um padrão mínimo de qualidade de ensino" (Ato das Disposições Constitucionais Transitórias - ADCT, art.60, \ $4^{\circ}$ ).

\section{O PADRÃO MÍNIMO DE QUALIDADE NA LEGISLAC̣ÃO BRASILEIRA}

Assegurar aos cidadãos deste país uma educação pública de qualidade tem sido uma preocupação histórica do povo brasileiro. Tal preocupação está expressa na Constituição Federal de 1988, quando obriga o Estado brasileiro não apenas a vincular percentual de recursos orçamentários destinados a esse fim, mas exige, ainda, um conjunto de responsabilidades referentes à gestão dos sistemas educacionais com o objetivo de assegurar uma educação de qualidade. A Carta Magna define que a União deverá atuar nos estados e municípios de forma "[...] redistributiva e supletiva, de forma a garantir a equalização de oportunidades educacionais e padrão mínimo de qualidade do ensino" (BRASIL, 1988, art. 211, \$1 ${ }^{\circ}$ ). O Plano Nacional de Educação (2001 - 2010) define a integração das ações do Poder Público de forma a conduzir à melhoria da qualidade do ensino (art.214, III). Já a Lei do Fundef ${ }^{3}$ estabelecia que a União, os Estados, o Distrito Federal e os Municípios ajustariam, progressivamente em um prazo de cinco anos, suas contribuições ao Fundo, de forma a garantir um valor por aluno correspondente a um padrão mínimo de qualidade de ensino, definido nacionalmente (BRASIL, 1996a, art.60, \ $4^{\circ}$ ). A Lei de Diretrizes e Bases da Educação Nacional - LDB no 9.394/96 reafirma o preceito constitucional de garantia de padrão de qualidade como princípio de ensino, incluindo entre os deveres do Estado para com a educação escolar pública a garantia de "padrões mínimos de qualidade de ensino, definidos como a variedade e quantidade mínimas, por aluno, de insumos indispensáveis ao desenvolvimento do processo de ensino-aprendizagem.” (BRASIL, 1996a, art.4, IX).

A Emenda Constitucional no 53 (de 19 de dezembro de 2006, altera, no Art. $2^{\circ}$, o art. 60 do Ato das Disposições Constitucionais Transitórias - ADCT) determina, no $\$ 1^{\circ}$, que: "A União, os Estados, o Distrito Federal e os Municípios deverão assegurar, no financiamento da educação básica, a melhoria da qualidade de ensino, de forma a garantir padrão mínimo definido nacionalmente" (BRASIL, 2006). No ano seguinte, a lei que regulamenta o Fundo de Manutenção e 
Desenvolvimento da Educação Básica - Fundeb (Lei nº 11.494, de 20 de junho de 2007), no \20 do artigo 4, determina que "o valor anual mínimo por aluno será definido nacionalmente, considerando-se a complementação da União, após a dedução da parcela que trata o art. $7^{\circ}$ desta lei, relativa a programas direcionados para a melhoria da qualidade da educação básica" (BRASIL, 2007).

A Emenda Constitucional (EC) n 59, de 11 de novembro 2009, que altera o $\$ 3^{\circ}$ do artigo 212 da Constituição Federal, ao fazer referência a padrão de qualidade, assim estabelece: "A distribuição dos recursos Públicos assegurará prioridade ao atendimento das necessidades do ensino obrigatório, no que se refere a universalização, garantia de padrão de qualidade e equidade, nos termos do plano nacional de educação" (BRASIL, 2009). Por essa EC, o ensino obrigatório passa a ser dos 4 aos 17 anos, portanto, da pré-escola ao ensino médio.

A Câmara de Educação Básica do Conselho Nacional de Educação (CNE) aprovou, em 5 de maio de 2010, o Parecer $n^{\circ}$ $8 / 2010$, tratando dos padrões mínimos de qualidade de ensino para a educação básica pública e estabelecendo as normas para a aplicação do inciso IX do artigo $4^{\circ}$ da Lei 9.394/96. O referido parecer incorporou o estudo do Custo Aluno Qualidade Inicial (CAQi), desenvolvido pela Campanha Nacional pelo Direito à Educação. Os valores do CAQi correspondem aos valores mínimos para o provimento de uma educação de qualidade. São calculados considerando os insumos indispensáveis ao desenvolvimento do ensino, bem como as especificidades de custo das diversas etapas e modalidades da educação básica. Não são considerados os custos referentes à implantação (aquisição de terreno, construção do prédio, compra de equipamentos e material permanente). O CAQi, uma vez implantado, deve contribuir para o enfrentamento das desigualdades regionais da educação brasileira. No entanto, devese ressaltar que o Parecer do CNE nunca foi homologado pelo Ministro da Educação, sendo pauta de lutas dos movimentos sociais e fator de posicionamento político nas Conferências municipais, intermunicipais e estaduais de educação, ocorridas em 2013.

A necessidade de se cumprir a legislação quanto à qualidade do ensino motivou prefeitos de todas as regiões do Brasil, reunidos em Brasília, ainda em maio de 1999, durante o Seminário dos Municípios, realizado pela Confederação Nacional de Municípios (CNM), a proporem, entre outras ações, a intensificação de estudos e a realização de pesquisa sob a responsabilidade do MEC, para a definição, o mais rápido possível, de um gasto anual por aluno que garantisse padrão de qualidade para o ensino, nos termos da CF, LDB e Lei do Fundef, em observância à legislação educacional da época. 
As demandas daqueles prefeitos se fundamentavam em bases práticas, pois queriam que as pesquisas definissem um valor que correspondesse a um gasto anual por aluno que garantisse um padrão de qualidade na educação para que pudessem levar educação de qualidade para seus munícipes. $\mathrm{Na}$ contramão desse padrão de qualidade, na prática, o financiamento da educação no Brasil não tem correspondido às demandas que a Constituição e a legislação educacional estabelecem.

\section{O FINANCIAMENTO DA EDUCAÇÃO BÁSICA A PARTIR DE 1998}

A partir da Constituição Federal de 1988 (CF/88), Estados, Municípios e o Distrito Federal deveriam aplicar em educação, no mínimo, $25 \%$ da receita resultante de impostos, compreendida a receita proveniente de transferências, na manutenção e desenvolvimento do ensino. A CF/88 delegou aos Municípios atuação prioritária na Educação Infantil e no Ensino Fundamental; aos estados e Distrito Federal delegou a atuação prioritária no Ensino Fundamental e no Ensino Médio. Com relação ao texto constitucional, apesar de ele estabelecer (entre 1988 a 1996) que metade da referida receita constitucional deveria ser aplicada na erradicação do analfabetismo e na universalização do Ensino Fundamental, conforme o art. 60 do Ato das Disposições Transitórias da CF de 1988, na prática, os entes federados tinham liberdade para escolher onde aplicar seus recursos em menor ou maior proporcionalidade (na Educação Infantil, no Ensino Fundamental ou no Ensino Médio). Mais tarde, no entanto, com a instituição do Fundef (de 1998 até 2006), o nível de ensino privilegiado passou a ser o Ensino Fundamental, pois os $25 \%$ destinados à educação, deveriam ser aplicados na seguinte proporção: no mínimo 15\% no Ensino Fundamental e no máximo 10\% nas demais etapas e modalidades da Educação Básica ou no Ensino Superior. O foco do Fundef no Ensino Fundamental teve impacto positivo nas matrículas, o qual possibilitou, em poucos anos, a quase universalização dessa etapa da Educação Básica (98\%). A priorização do ensino fundamental prejudicou o atendimento da Educação Infantil, do Ensino Médio e da Educação de Jovens e Adultos.

Com a instituição da Lei de Diretrizes e Bases da Educação Nacional (LDB), em 1996, foram reafirmadas as determinações constitucionais quanto ao atendimento prioritário dos municípios na Educação Infantil e Ensino Fundamental e aos estados, prioritariamente, o ensino médio a todos que o demandarem. 
Convém destacar que o ensino fundamental, embora sendo uma prioridade para o atendimento dos municípios, deve ser assegurado pelos estados, ou seja, essa etapa do ensino pode ser oferecida tanto pelas redes municipais quanto pelas redes estaduais.

Depois da LDB de 1996, segundo Sales e Silva (2013), houve uma movimentação natural de matrículas da Educação Infantil dos Estados para os municípios e as matrículas dos Municípios que atendiam o Ensino Médio foram transferidas para as redes estaduais. Portanto, no caso da Educação Infantil e do Ensino Médio, não houve necessidade de as redes estaduais e municipais disputarem esses atendimentos. Em alguns Estados, essa disputa ocorreu em busca dos alunos do ensino fundamental, havendo uma tendência de os municípios se destacarem no atendimento dos anos iniciais do Ensino Fundamental e os Estados se destacarem no atendimento dos anos finais. Essa disputa ganhou um elemento novo após a publicação da lei do Fundef e do conhecimento da lógica do referido fundo, a qual estimulou uma "corrida" em busca de se ampliar o atendimento no Ensino Fundamental. Por essa lógica, cada aluno contabilizado no Censo Escolar do ano anterior era revertido em receita no ano seguinte. Nesse caso, qualquer aumento na quantidade de alunos já em 1997 representaria aumento nas receitas de Estados e Municípios em 1998.

Em 1996, estava desenhado o novo cenário do financiamento da educação pública no Brasil, dando início ao fenômeno das transferências de matrículas das redes estaduais para as municipais, que ficou conhecido como municipalização do ensino. A matriz de financiamento colocou em cena uma lógica de capitação de recursos para educação altamente indutora em relação ao crescimento da oferta do Ensino Fundamental no Brasil, praticamente universalizando essa etapa da Educação Básica em poucos anos da implementação da política de fundos. Essa política, embora tenha trazido muitas vantagens, comprometeu a expansão do atendimento do Ensino Médio e da Educação Infantil, duas etapas importantes da educação básica dos brasileiros.

É importante observar que os municípios, apesar de não serem pessoas físicas, por serem dirigidos por pessoas, são sensíveis aos mesmos interesses econômicos da lógica motivacional do homem. Para realizar mais, essas pessoas buscam a todo custo tomar as melhores decisões que tragam mais vantagens financeiras para o município que dirigem, nem que para isso tenham que fazer escolhas que não sejam as melhores para o conjunto da população. Talvez aí resida o principal problema das políticas indutoras, a partir da avaliação que se faz da implementação do Fundef. 


\section{A LÓGICA DO FUNDEF/FUNDEB}

No mesmo ano em que entrou em vigor a LDB/96, foi aprovada a Emenda Constitucional n ${ }^{\circ} 14$, que criava o Fundef, e a Lei 9.424, que o regulamentava. Embora o Fundef tenha entrado em vigor, em todo País, apenas em janeiro de 1998, seu impacto nas matrículas já podia ser sentido, mesmo antes de sua instituição, uma vez que toda a legislação do Fundef já havia sido publicada. Portanto, as novas regras do financiamento da educação pública já eram do conhecimento de todos, especialmente do conhecimento dos estados e dos municípios.

Nesse sentido, com a vigência do Fundef, a lógica do financiamento das escolas públicas da educação básica mudou no Brasil. A partir de então, foi criado, no âmbito de cada Estado, um fundo de natureza contábil, composto por 15\% de alguns impostos (ICMS, IPI-Exp., Compensação pela Desoneração das Exportações) e mais $15 \%$ do FPM e do $\mathrm{FPE}^{4}$, sendo que o recolhimento do FPM era para os municípios e o recolhimento de FPE era para os Estados. A arrecadação desse fundo era rateada entre as redes de ensino (estadual e municipal), de forma proporcional à quantidade de alunos matriculados no ano anterior. Portanto, quanto mais matrículas, mais receita uma rede de ensino receberia. Em função dessa lógica de proporcionalidade de matrículas, estabeleceu-se uma disputa por aluno do Ensino Fundamental. Nesse sentido, cada rede de ensino procurava ampliar seu atendimento. Muitas campanhas publicitárias foram feitas para atrair alunos que não estivessem matriculados. Tudo era feito pelas redes estaduais e municipais para ampliar suas matrículas, uma vez que no contexto de um mesmo município geralmente havia escolas municipais e estaduais realizando o mesmo atendimento.

Assim, dependendo do contexto de cada estado, as matrículas do Ensino Fundamental passaram a ser objeto de municipalização ou alvo de disputa entre estado e município. O processo de municipalização no Brasil, segundo Arelaro (2005, p.1042), não segue uma distribuição homogênea e é mais acentuado na região Nordeste.

Ainda sobre as receitas do Fundef, o Tesouro Nacional realizava cálculos para determinar o valor per capita no âmbito de cada estado. Para tanto, dividia o total arrecadado no estado (a soma das contribuições para o Fundef do estado e de seus municípios) pelo total de alunos matriculados no Ensino Fundamental no ano anterior. Portanto, o valor per capita era diretamente proporcional ao valor arrecadado pelo fundo do Estado e inversamente proporcional às suas matrículas. Nos estados em que o valor per capita encontrado fosse menor que o valoraluno fixado anualmente pela União, esta deveria repassar recursos 
(complementação) para o fundo daquele estado até igualar o valor per capita pelo valor aluno/ano fixado pela União. Durante o Fundef e agora com o Fundeb, o Estado do Piauí sempre recebeu complementação da União. Por possuir uma economia fraca (arrecadava um volume pequeno de impostos), consequentemente contribuía muito pouco para o Fundef e vem contribuindo muito pouco para o Fundeb. Segundo Davies (2001), o Fundef se limitou a transferir recursos entre as redes do mesmo estado. A participação da União, via complementação, ficou bastante longe de servir como mecanismo de aumento de recursos a serem aplicados em educação como forma de equalização.

O que mudou na passagem do Fundef para o Fundeb a partir de 2007? Segundo Bassi e Fermino (2011, p.11),

o Fundeb preservou os mecanismos de captura e de redistribuição de recursos instaurados pelo Fundef. Estendeu, porém, significativamente a abrangência de financiamento a todas as etapas e modalidades da educação básica, contando, para isso, com um maior aporte de recursos decorrente da elevação do percentual subvinculado de um número maior de impostos (BRASIL, 2007). Implantado também em âmbito estadual, os novos fundos processam operações contábeis que recolhem a maior parte da receita gerada pela vinculação que os Estados, o DF e os Municípios têm de destinar às despesas com MDE e, depois, as redistribui aos governos, proporcionalmente de acordo com o número de matrículas de Educação Básica, obedecendo às competências estabelecidas no artigo 211 da CF/88.

Tanto no Fundef quanto no Fundeb, o governo federal passou a fixar anualmente um valor mínimo nacional por aluno (valor aluno/ano), para atender os estados em que seus valores per capita não atingiam o referido valor mínimo nacional, atendimento esse que ficou conhecido como complementação da União.

Até o ano de 1999, o valor aluno/ano, fixado pelo Governo Federal, era o mesmo para todos os níveis do Ensino Fundamental. De 2000 até 2004, o valor aluno/ano passa a considerar um valor para os anos iniciais do Ensino Fundamental e outro valor (5\% maior) para os anos finais, recompensando mais os entes federados que mais atendiam os referidos anos finais. De 2005 a 2006, o valor aluno/ano começa a considerar a localidade da escola (zona urbana e zona rural), passando a apresentar quatros valores: anos iniciais urbanos, anos iniciais rurais, anos finais urbanos e anos finais rurais, agora, recompensando mais pelos alunos da zona rural, pois o valor aluno/ano passou a ser $20 \%$ maior, em relação aos alunos da zona urbana. A partir de 2007, foi instituído o Fundeb e desde então toda a Educação Básica passou a ser contemplada com recursos do fundo. $\mathrm{O}$ valor aluno/ano passou a contemplar mais etapas e modalidades do referido nível de ensino, criando, assim, fatores de ponderação entre as etapas e modalidades. 
A etapa da Educação Básica usada como base para o cálculo são os anos iniciais do Ensino Fundamental urbano, com fator de ponderação 1,00 (um). As outras etapas e modalidades possuem fatores menores ou maiores que 1,00 (um), conforme define, em cada ano, a Comissão Intergovernamental de Financiamento para a Educação Básica de Qualidade, que é composta por representantes das Secretarias Estaduais (05) e Municipais (05) de Educação, mediante representação do Consed ${ }^{5}$ e da Undime ${ }^{6}$, sendo um de cada região do país, além de um representante do Ministério da Educação.

No primeiro ano de vigência do Fundeb (2007), os fatores de ponderação variavam entre 0,7 e 1,3 e, a partir de 2009, esses limites apresentaram pequena variação - o limite inferior subiu de 0,7 para 0,8 e o limite superior permaneceu em 1,3. De 2008 para 2009, não houve reajustes significativos nos fatores. A modalidade que registrou maior crescimento no indicador foi a Educação de Jovens e Adultos integrada à educação profissional. $O$ fator passou de 0,70 para 1,00. Isso significa que, em 2008, os valores repassados, anualmente, por esses alunos da Educação de Jovens e Adultos (EJA) correspondiam a $70 \%$ do custo do estudante das séries iniciais urbanas, sendo que, em 2009, os alunos da EJA, integrada à educação profissional de nível médio, com avaliação no processo, passaram a equivaler o mesmo valor dos alunos dos anos iniciais do Ensino Fundamental urbano, ou seja, $\mathrm{R} \$ 1.227,17$. Com o Fundeb, a diferença entre o valor aluno/ ano dos anos iniciais e dos anos finais do ensino fundamental cresceu de $5 \%$ para $10 \%$, tornando as matrículas deste segmento ainda mais atrativas para os entes federados que mais atendiam esta etapa do Ensino Fundamental. Em relação à Educação Infantil, a pré-escola em tempo parcial, o fator de ponderação durante os anos de 2007 e 2008 foi 0,9 e subiu nos anos seguintes para 1,0. O fator de ponderação da creche em tempo parcial permaneceu o mesmo valor $(0,8)$ de 2007 a 2013. Para 2014, a Comissão Intergovernamental de Financiamento para a Educação Básica de Qualidade, reunida em 16 de outubro de 2013, fez duas alterações nos fatores de ponderação: (1) elevou o fator de ponderação da creche de 0,8 para 1,0 e (2) elevou de 1,20 para 1,25 o fator de ponderação do Ensino Médio urbano. Em relação ao fator de ponderação da creche, embora tenha sido elevado de 0,8 para 1,0 , ainda permanece bem distante do valor real gasto pelos entes federados para atender esta etapa da Educação Básica.

Segundo Farenzena (2005), o custo aluno das creches é mais elevado que o custo das pré-escolas. Ademais, para Leite (2007, p.3), os custos da educação infantil "são superiores ao praticado nas outras 
etapas da educação básica. Desconsiderando essa realidade, o governo tem recorrentemente fixado para a educação infantil valores menores aos praticados no ensino fundamental". Para Pinto (2007, p.891), os critérios utilizados para a definição dos fatores de ponderação não refletem o custo real das etapas e modalidades da Educação Básica, o que prevaleceu "foi uma decisão política que teve como parâmetro a busca de um acordo mínimo entre estados e municípios".

Para o governo federal aproximar os fatores de ponderação da realidade dos custos da educação brasileira, é necessário um volume maior de recurso para a educação. A Nota Técnica apresentada, em 2011, pela Campanha Nacional pelo Direito à Educação (CAMPANHA NACIONAL PELO DIREITO À EDUCAÇÃO, 2011), "Por que $7 \%$ do PIB para a educação é pouco? Cálculo dos investimentos adicionais necessários para o novo PNE garantir um padrão mínimo de qualidade", bem como a Nota Técnica apresentada, em 2013, pela Associação Nacional de Pesquisa em Financiamento da Educação (FINEDUCA, 2013), intitulada "Por que a união deve complementar o CAQi no PNE? Cálculo do quanto a união deve complementar os recursos do Fundeb para garantir um padrão mínimo de qualidade a todos/as os/as estudantes da educação básica" justificam tecnicamente a necessidade de um aporte maior de recursos para área de educação.

Apesar da constatação da necessidade de mais recursos para a educação, pode-se observar que, com o Fundeb, houve um avanço em relação ao Fundef, no que diz respeito à melhoria dos fatores de ponderação que definem os valores pagos por aluno/ano em cada etapa e modalidade da educação básica, assim como na participação da União. Segundo Araújo (2012, p. 30),

o Fundeb conseguiu ser eficiente na redução da desigualdade entre os valores por aluno via aumento da complementação da União para os fundos estaduais com menor capacidade de arrecadação. Porém, o Fundo não foi suficiente para diminuir a desigualdade efetiva entre as Regiões, pois a existência de recursos próprios concentrados nos estados das Regiões mais ricas permite a manutenção de significativas diferenças de valor por aluno destas em relação aos estados de Regiões mais pobres.

Neste artigo, é dada ênfase, em termos empíricos, ao valor aluno/ano da Educação Infantil. Para tanto, é apresentado inicialmente um breve histórico do processo de ampliação do atendimento da educação infantil em Teresina. Na sequência é apresentado o cálculo do valor aluno/ano e o custo total de toda a Rede Pública Municipal de Educação Infantil de Teresina e, finalmente, é feita uma comparação do valor aluno/ano encontrado com o CAQi (Custo Aluno Qualidade Inicial), conforme Pinto (2013). 


\section{O PROCESSO DE MUNICIPALIZAC̣ÃO DA EDUCAÇÃO INFANTIL EM TERESINA}

Até 2006, o atendimento da Educação Infantil realizado pela Prefeitura Municipal de Teresina (PMT) esteve a cargo da área de assistência social, executado pela Secretaria Municipal da Criança e do Adolescente (SEMCAD), hoje denominada Secretaria Municipal do Trabalho, Cidadania e de Assistência Social (SEMTCAS). O atendimento da préescola acontecia, portanto, por meio de convênio entre a PMT e inúmeras associações comunitárias, instituições filantrópicas e confessionais. Assim, essas pré-escolas embora sendo privadas, à época, recebiam recursos da PMT para ajudar nas despesas de manutenção do ensino.

Naquele ano, com as discussões sobre a instituição do Fundeb, que certamente aconteceria no ano seguinte (2007), a Secretaria Municipal de Educação de Teresina (SEMEC) encomendou estudo com vistas a avaliar o impacto financeiro da incorporação dessas pré-escolas à rede municipal. O referido estudo recomendou tal incorporação, uma vez que, com o Fundeb, o município passaria a receber recursos por cada aluno matriculado na Educação Infantil. Tal recomendação foi posta em prática já no início do Fundeb (2007), a qual pode ser percebida nas Tabelas (1 e 2) a seguir:

\section{TABELA 1}

Matrícula Educação Infantil (Creche) em Teresina por dependência administrativa

\begin{tabular}{lrrrrrrrr} 
& $\mathbf{2 0 0 6}$ & $\mathbf{2 0 0 7}$ & $\mathbf{2 0 0 8}$ & $\mathbf{2 0 0 9}$ & $\mathbf{2 0 1 0}$ & $\mathbf{2 0 1 1}$ & $\mathbf{2 0 1 2}$ & $\mathbf{2 0 1 3}$ \\
Estadual & 0 & 86 & 23 & 18 & 96 & 37 & 66 & 0 \\
Federal & 0 & 0 & 0 & 0 & 0 & 0 & 0 & 0 \\
Municipal & 1.746 & 5.203 & 6.441 & 6.971 & 7.163 & 8.689 & 10.656 & 10.422 \\
Privada & 3.425 & 1.915 & 1.607 & 2.252 & 1.631 & 1.740 & 2.191 & 2.551 \\
Total & 5.171 & 7.204 & 8.071 & 9.241 & 8.890 & 10.466 & 12.913 & 12.973 \\
\hline
\end{tabular}

Fonte: Inep.

\section{TABELA 2}

Matrícula Educação Infantil (Pré-escola) em Teresina por dependência administrativa

\begin{tabular}{lrrrrrrrr}
\hline & 2006 & 2007 & 2008 & 2009 & 2010 & 2011 & 2012 & 2013 \\
Estadual & 590 & 462 & 545 & 303 & 116 & 56 & 0 & 0 \\
Federal & 0 & 0 & 0 & 0 & 0 & 0 & 0 & 0 \\
Municipal & 8.103 & 13.200 & 14.798 & 14.594 & 14.618 & 14.723 & 13.504 & 15.224 \\
Privada & 17.194 & 9.519 & 9.223 & 9.119 & 9.213 & 8.832 & 8.087 & 8.244 \\
Total & 25.887 & 23.181 & 24.566 & 24.016 & 23.947 & 23.611 & 21.770 & 23.468 \\
\hline
\end{tabular}

Fonte: Inep. 
$\mathrm{Na}$ Tabela 2, pode-se observar a redução gradual das matrículas da Educação Infantil da rede estadual, no município de Teresina. Saindo de 590 matrículas em 2006, para nenhum aluno em 2012. Vale destacar que, em 2004, a referida rede possuía em torno de 6000 matrículas, caindo para 2000 matrículas no ano de 2005 . No ano que inicia a Tabela 2 (2006), as matrículas são fortemente reduzidas para 590.

Considerando as redes municipal e privada, a partir da análise das Tabelas 1 e 2, pode ser verificado que as matrículas da Rede Municipal de Teresina, em 2007, ultrapassaram, em muito, as matrículas da rede privada, tanto nas Creches quanto nas Pré-escolas. Nos anos seguintes, observa-se ainda uma tendência de estabilização das matrículas na rede privada e um crescimento na rede municipal.

A decisão tomada pelo município de Teresina de incorporar as pré-escolas conveniadas à rede municipal e de ampliar o atendimento da Educação Infantil não foi a mesma tomada pelas demais capitais nordestinas, conforme matrículas apresentadas na Tabela 3, a seguir:

\section{TABELA 3}

Matrículas ${ }^{7}$ das redes Municipal e Privada das capitais nordestinas em 2013

\begin{tabular}{llrc}
\hline Município & Dependência & Ed.Infantil & $\begin{array}{c}\text { Relação rede } \\
\text { Municipal/Privada }\end{array}$ \\
\hline RECIFE & Municipal & 15.002 & \\
SAO LUIS & Privada & 35.047 & 0,43 \\
& Municipal & 14.872 & \\
MACEIO & Privada & 32.990 & 0,45 \\
& Municipal & 6.860 & \\
SALVADOR & Privada & 12.991 & 0,53 \\
FORTALEZA & Municipal & 17.902 & \\
& Privada & 33.924 & 0,53 \\
NATAL & Municipal & 32.253 & \\
& Privada & 57.666 & 0,56 \\
ARACAJU & Municipal & 10.227 & \\
& Privada & 15.274 & 0,67 \\
JOAO PESSOA & Municipal & 6.349 & \\
TERESINA & Privada & 7.867 & 0,81 \\
& Municipal & 8.301 & \\
\hline & Privada & 10.130 & 0,82 \\
\hline & Municipal & 25.573 & 2,38 \\
\hline
\end{tabular}

Fonte: Inep. 
Passados sete anos de instituição do Fundeb, Teresina foi a capital nordestina que mais ampliou seu atendimento na Educação Infantil em relação à rede privada (2,38 vezes maior $)^{8}$. João Pessoa e Aracaju foram as capitais que, depois de Teresina, proporcionalmente mais ampliaram sua oferta na Educação Infantil, respectivamente ${ }^{9} 0,82$ e 0,81 vezes menor que a rede privada. Essa tendência de a maioria dos municípios nordestinos não ampliarem o atendimento na Educação Infantil possivelmente tem uma explicação econômica. $\mathrm{Na}$ sequência, esse artigo se propõe a analisar essa questão, tomando como referência o município de Teresina, que, conforme Alves e Silva (2013), é a segunda capital brasileira a atingir a meta do PNE 2001-2010 da população de 4 e 5 anos (88,1\% - superando a meta de 80,0\%), ficando atrás apenas de Vitória com $90,7 \%$ de atendimento na referida faixa etária.

\section{O CUSTO ALUNO/ANO DA EDUCAÇ̃̃O INFANTIL DE TERESINA}

Para verificar se é viável economicamente a opção tomada pela Rede Pública Municipal de Ensino de Teresina de ampliar fortemente o atendimento na Educação Infantil, foi realizado um estudo do custo aluno/ano da Educação Infantil, envolvendo todos os Centros de Municipais de Educação Infantil, tomando-se como recorte temporal o ano de 2012.

No citado ano, a Rede Pública Municipal de Ensino de Teresina/PI possuía 302 unidades de ensino, sendo 150 escolas de ensino fundamental e 152 Centros Municipais de Educação Infantil - CMEIs. Assim, para concretização deste trabalho, foram considerados, no referido estudo, todos os CMEIs ativos no ano de 2012, localizados tanto na zona rural quanto na zona urbana.

Para calcular o custo aluno/ano, foi utilizado o método de ingredientes, o qual busca analisar os dados partindo do todo para as partes por meio de um processo de desagregação contínua; dessa forma, foi possível identificar o valor-custo de cada insumo. Este valor individual, novamente agregado, permitiu encontrar o custo aluno-ano da Educação Infantil de cada CMEI e, consequentemente, da Rede, considerando, neste levantamento censitário, as 152 unidades de ensino caracterizadas como instituição educacional infantil que atendem crianças de até 5 anos de idade, no ano em estudo. Foram definidas desagregações para cada uma das categorias de insumos. Segundo Verhine (2005, p. 62),

Esta abordagem parte do geral para o específico, via desagregações consecutivas, até o ponto em que se possa identificar, sem ambigüidade, o valor-custo de cada ingrediente [...]. Uma vez especificados todos os ingredientes, eles podem ser avaliados pelo conceito de oportunidade. Agregando-se novamente, ou seja, somando-se os valores unitários obtidos dos ingredientes, tem-se o custo total da intervenção. 
Em relação às pesquisas sobre custos educacionais, a maioria delas apresenta em comum a dificuldade, maior ou menor, na obtenção dos dados - seja por coleta direta nas escolas (a maioria não possui dados sobre o custo de seu funcionamento, principalmente no que se refere ao pagamento de pessoal docente ou não docente) seja por coleta na Secretaria de Educação, onde a burocracia ou o acúmulo de trabalho para equipes, reduzidas de certa forma, comprometem o acesso aos dados em tempo hábil. No entanto, o levantamento de custos educacionais é fundamental para subsidiar as ações dos governos e legisladores da área da educação na destinação dos recursos por etapas e modalidades de ensino.

Em relação à coleta de dados da pesquisa que fundamenta este artigo, não foi possível levantar todos os itens de custos dos 152 CMEIs, uma vez que seria uma tarefa bastante árdua. Por isso, com a finalidade de reduzir o trabalho e de viabilizar o estudo, sem comprometê-lo, optou-se por excluir do levantamento os custos de implantação do imóvel, que, para Xavier e Marques (1988, p.15), são os custos que contemplam "planejamento, aquisição de terreno, projetos arquitetônicos e de engenharia, obras de infraestrutura, construção do prédio e aquisição de materiais necessários à instalação"; como também os custos privados com a educação, que são os custos correspondentes aos gastos individuais das famílias com material escolar, vestuário e traslado para a escola. Portanto, este estudo utilizou o conceito de custo enquanto "recursos ou meios utilizados para a oferta do serviço educacional, expressos em valores monetários" (FARENZENA; MACHADO, 2006, p. 279), tendo em vista que esse conceito, segundo Alves (2012, p. 92),

atende os requisitos das políticas de financiamento da educação ao oferecer parâmetros para o cálculo do montante de recursos que o Estado deve despender com o funcionamento de suas escolas, ou seja, focaliza o fluxo de recursos que realmente deve haver para a manutenção delas.

Em estudo anterior, realizado por Silva (2008), a autora pesquisou os custos de 17 escolas do Ensino Fundamental da mesma rede de ensino de Teresina. Dentre as categorias levantadas, Silva incluiu os insumos referentes à implantação dos prédios escolares.

Para o cálculo do custo aluno-ano dos Centros Municipais de Educação Infantil - CMEIs de Teresina/PI, no ano de 2012, foram utilizados os insumos que estão relacionados efetivamente às despesas de cada um dos CMEIs no ano em estudo. No levantamento das informações necessárias para esee cálculo, estabeleceu-se um plano de coleta dos dados envolvendo as categorias abaixo definidas, por representarem os custos diretos e indiretos com a Educação Infantil: 
a) profissionais da educação: inclui os professores e pessoal administrativo efetivos, estagiários e terceirizados, bem como os encargos.

b) merenda e transporte escolar: considera nesta categoria os recursos federal e municipal (contrapartida da Prefeitura);

c) livro didático: material adquirido com recursos próprios, uma vez que o Programa Nacional do Livro Didático (PNLD) ainda não é fornecido para Educação Infantil;

d) recursos financeiros oriundos do governo federal e do tesouro municipal: Programa Dinheiro Direto na Escola (PDDE); PDDE Acessibilidade e Fundo Rotativo;

e) outros insumos: água, energia, telefone e gás; e

f) despesas com a administração da Secretaria Municipal de Educação: compreendendo as despesas com profissionais efetivos, terceirizados e estagiários; despesas com aluguel de prédios; água, energia, telefone e gás.

Os custos burocráticos, definidos na literatura como custos indiretos, compreendem-se como as despesas realizadas pela Secretaria Municipal de Educação - SEMEC, concebida como órgão gestor central da Rede Pública Municipal de Ensino.

Para o cálculo do custo aluno/ano dos 152 Centros Municipais de Educação Infantil da Rede, fez-se necessário identificar os elementos de despesas de cada unidade. No entanto, não só foram considerados apenas os insumos de custo direto de funcionamento dos CMEIs (XAVIER; MARQUES, 1988), mas também foram considerados alguns itens de custos indiretos com a administração da sede da Secretaria Municipal de Administração.

Para compreensão dos custos com a Educação Infantil, fizeram-se necessárias a desagregação e a agregação de todos os itens das categorias definidas para análise e o cálculo aproximado dos custos diretos e indiretos dos 152 CMEIs. A análise das despesas com os elementos que formam cada uma das seis categorias investigadas contribuiu para a compreensão do peso de cada insumo na composição do valor do custo aluno/ano da Educação Infantil da Rede Pública Municipal de Ensino de Teresina em 2012.

A Tabela 4 abaixo mostra a contribuição percentual de despesa de cada uma das categorias pesquisadas, as quais compõem o custo aluno/ano médio da Educação Infantil da Rede de Ensino em estudo. A categoria Profissionais da Educação é a categoria de maior impacto na composição do custo aluno/ano, correspondendo a $79,9 \%$ do valor total das despesas. Sua composição inclui as despesas com salários e encargos contratuais dos servidores efetivos, 
terceirizados e estagiários, docentes e não docentes. O percentual observado nesta categoria $(79,9 \%)$ corrobora os resultados de outras pesquisas, as quais concluem que as despesas com pessoal ficam em torno dos 80\% (GOUVEIA et al, 2005; SALES et al, 2005; VERHINE, 2005). É importante destacar que, nas pesquisas consultadas, quando são incluídos os custos das instalações das escolas, esse percentual cai para $70 \%$, aproximadamente.

A categoria seguinte, Merenda e Transporte Escolar (9,3\%), inclui os recursos federais e os recursos próprios. Em terceiro lugar aparece a categoria Administraşão da Secretaria com 4,3\%. A categoria Outros Insumos $(2,8 \%)$ aparece em quarto lugar, incluindo água, energia elétrica, telefone e gás de cozinha; sendo 1,9\% com despesas referentes à aquisição de Livro Didático e 1,7\% com as despesas custeadas com Recursos Federais e do Município, incluindo verbas federais do Programa Dinheiro Direto na Escola (PDDE) e PDDE Acessibilidade, bem como verbas municipais oriundas do Fundo Rotativo, para o custeio das escolas.

\section{TABELA 4}

Categorias de despesas que compõem o custo aluno/ano médio da Educação Infantil da Rede Pública Municipal de Ensino de Teresina em 2012 $2^{10}$

\begin{tabular}{|c|c|c|c|}
\hline CATEGORIAS & TOTAL (R\$) & CUSTO ALUNO|ANO & $\%$ \\
\hline Profissionais da Educação & $50.180 .395,13$ & $2.117,23$ & 79,9 \\
\hline Merenda e Transporte Escolar & $5.836 .420,31$ & 246,25 & 9,3 \\
\hline Despesas com a Administração & $2.715 .847,57$ & 114,59 & 4,3 \\
\hline Outros Insumos & $1.777 .935,67$ & 75,02 & 2,8 \\
\hline Livro Didático & $1.177 .015,50$ & 49,66 & 1,9 \\
\hline Recursos Federais e do Município & $1.096 .384,10$ & 46,26 & 1,7 \\
\hline TOTAL & $62.840 .641,62$ & $2.651,39$ & \\
\hline
\end{tabular}

Fonte: Elaborado pelos autores deste trabalho.

O custo total com os CMEIs em 2012 atingiu o valor de $\mathrm{R} \$$ 62.840.641,62 e apresentou um custo aluno/ano médio de R\$ 2.651,39. Para encontrar o custo efetivo do município de Teresina, é preciso subtrair desses valores as parcelas referentes aos recursos federais (merenda, transporte e PDDE). Fazendo esse procedimento, o custo efetivo do município de Teresina com o atendimento da Educação Infantil apresentou os seguinte valores: custo total de $\mathrm{R} \$$ 60.087.514,28 e custo aluno/ano médio de $\mathrm{R} \$ 2.535,23$. 
Para determinar o valor referente à receita proveniente do Fundeb por cada aluno da Educação Infantil, foram utilizados as matrículas de 2011 e os valores pagos por aluno/ano, conforme memória de cálculo apresentada na Tabela 5.

\section{TABELA 5}

Receita proveniente do Fundeb em 2012 referente às matrículas da Educação Infantil, do ano anterior (2011)

\begin{tabular}{llrrr}
\hline \multicolumn{1}{c}{ EDUCAC̣̃̃ INFANTIL } & $\begin{array}{c}\text { VALOR } \\
\text { ALUNO } \\
\text { R\$ }\end{array}$ & MATRÍCULA & TOTAL R\$ \\
\hline Creche púb. em tempo integral (fator de pond. = 1,3) & $2.427,30$ & $265^{*}$ & $643.233,18$ \\
Creche púb.em tempo parcial (fator de ponderação = 0,8) & $1.493,72$ & 8.392 & $12.535 .298,24$ \\
Pré-Escola em tempo integral (fator de pond. = 1,3) & $2.427,30$ & $423^{*}$ & $1.026 .745,79$ \\
Pré-Escola em tempo parcial (fator de pond. = 1,0) & $1.867,15$ & 14.131 & $26.384 .696,65$ \\
Educação especial (fator de ponderação = 1,2) & $2.240,58$ & 245 & $548.942,10$ \\
\hline & TOTAL & & 23.456 & $\mathbf{4 1 . 1 3 8 . 9 1 5 , 9 5}$ \\
\hline
\end{tabular}

Fonte: Inep.

* As matrículas nos CMEls que funcionavam em tempo integral representam apenas 2,9\% do atendimento.

A partir da Tabela 5, pode-se calcular o valor aluno/ano médio do Fundeb (R \$ 1.753,88). No cálculo, levam-se em consideração os valores referentes aos fatores de ponderação, dividindo-se o valor da receita proveniente do Fundeb $(\mathrm{R} \$ 41.138 .915,95)$ pela quantidade de matrículas (23.456).

Para avaliar se as despesas do município de Teresina com a Educação Infantil foram compensadas pela receita proveniente do Fundeb, deve-se subtrair o custo total efetivo do município de Teresina do valor que recebeu como receita do Fundeb. Ao fazer essa subtração, encontra-se um valor negativo de $\mathrm{R} \$ 18.948 .598,33$. Essa cifra negativa corresponde ao valor que o município teve que arcar, com recursos próprios, para garantir o atendimento da Educação Infantil em 2012.

Finalmente, na Tabela 6, apresenta-se um resumo com 3 (três) tipos de custo aluno/ano. O primeiro corresponde ao montante de recursos encontrado neste estudo, referindo-se ao custo aluno/ano médio efetivo ( $\mathrm{R} \$ 2.535,23)$, que a Prefeitura Municipal de Teresina (PMT) investiu, em 2012, em média por CMEI. O segundo custo corresponde ao valor aluno/ano médio proveniente de receitas do Fundeb (R $\$ 1.753,88)$. O terceiro custo corresponde aos valores 
calculados pelo CAQi, referentes a Creche tempo parcial e Pré-escola tempo parcial. Para simplificar e sem trazer nenhum prejuízo para análise ${ }^{11}$, é importante destacar que foram utilizados, na Tabela 6 , valores do CAQi, conforme Pinto (2013), referentes ao tempo parcial, uma vez que a Rede Pública Municipal de Ensino de Teresina apresentava em 2012 pouquíssimas matrículas de Tempo Integral (2,9\%).

\section{TABELA 6}

Resumo dos valores aluno/ano em 2012

CUSTO ALUNO/ANO

Encontrado neste estudo

$2.535,23$

Recebido pelo Fundeb

$1.753,88$

Calculado pelo $\mathrm{CAOi}^{12}$

Para Creche tempo parcial

$5.097,29$

Para Pré-escola tempo parcial

$3.209,05$

Fonte: Elaborado pelos autores deste trabalho.

Analisando a Tabela 6, verifica-se que o custo aluno/ano médio efetivo que a PMT investiu em 2012, em média, por CMEI $(\mathrm{R} \$ 2.535,23)$ ficou $44,5 \%$ acima do valor aluno/ano médio proveniente do Fundeb ( $\mathrm{R} \$ 1.753,88)$. A diferença negativa de $\mathrm{R} \$ 781,35$ entre esses dois valores de custo evidencia o quanto é insuficiente o fator de ponderação da Educação Infantil, especificamente da Creche e da Pré-escola. O valor médio proveniente das receitas do Fundeb $(\mathrm{R} \$ 1.753,88)$ por aluno de cada CMEI ficou bem distante do valor do CAQi, o qual é considerado referência do padrão mínimo de qualidade da Educação Infantil. Considerando-se a Pré-escola, para o valor do CAQi de $\mathrm{R} \$ 3.209,05$, a diferença é negativa $(\mathrm{R} \$ 1.455,17)$. Essa diferença corresponde a $83 \%$ do quanto seria necessário para elevar o valor recebido do Fundeb para o atendimento das Préescolas municipais de Teresina. Considerando-se a Creche, para o valor do CAQi de $\mathrm{R} \$ 5.097,29$, a diferença é ainda maior e cresce negativamente para $\mathrm{R} \$ 3.343,41$. Tal diferença corresponde a $191 \%$; em outras palavras, é preciso aumentar em 2,91 vezes o valor médio proveniente do Fundeb para atingir o valor do CAQi.

Esse resultado está de acordo com o Relatório da Pesquisa Perfil dos Gastos Educacionais nos Municípios Brasileiros, coordenado por Araújo (2012), que afirma que a oferta de Educação Infantil da Região Nordeste se encontra muito distante de um padrão mínimo de qualidade, conforme Parecer da CEB/CNE no 8/2010. O mesmo relatório conclui 
que os efeitos negativos do referido atendimento, são mais evidentes na oferta da Educação Infantil, etapa em que as distâncias entre Sul/ Sudeste versus Norte/Nordeste foram bastante expressivas.

Tal constatação aumenta a necessidade do estabelecimento de um regime de colaboração entre os entes federados, de modo a equilibrar ou mesmo reduzir as desigualdades regionais.

\section{CONSIDERACְÕES FINAIS}

O estudo aqui apresentado tomou como referência de dados o ano de 2012 e foi realizado no município de Teresina, envolvendo toda rede pública municipal que realiza atendimento na Educação Infantil. $\mathrm{O}$ resultado empírico encontrou o custo total da referida rede e o valor médio do custo aluno/ano.

Constatou-se que o valor médio encontrado neste estudo para o custo aluno/ano da Rede Pública Municipal de Ensino de Teresina ficou 44,5\% ( $\mathrm{R} \$ 781,35)$ acima do valor médio proveniente de receitas do Fundeb por cada aluno matriculado na Educação Infantil em 2012. Tal constatação evidencia a insuficiência do fator de ponderação da Educação Infantil, especificamente da Creche e da Pré-escola, bem como o esforço desse município para ofertar essa etapa da Educação Básica.

Teresina é um município nordestino, capital de um dos estados mais pobres do Brasil, e que, pelo fato de ser capital, encontra-se numa situação um pouco melhor, em termos de arrecadação de impostos, que a maioria dos pequenos municípios da Região. Portanto, ofertar vagas na Educação Infantil deve demandar um esforço ainda maior para os pequenos municípios nordestinos.

A insuficiência de recursos apresenta-se como um dentre outros fatores que pode explicar porque as outras capitais nordestinas resistem em não ampliar o atendimento da Educação Infantil. Os gestores, usando a lógica das pessoas físicas comuns, sabem que para ofertar Educação Infantil com qualidade é necessário não só recursos para custeio, mas também mais recursos para investir em infraestrutura. Sobretudo sabem que muitos prédios, para atender aos padrões mínimos, precisarão ser construídos. Ademais, provavelmente "desconfiam" que o valor do CAQi, sendo aprovado e colocado em prática, não será suficiente, a curto prazo, para arcar com as despesas com a construção da infraestrutura necessária para o atendimento da Educação Infantil com a qualidade que a população há tantos anos reclama, que o Fundef durante 10 anos negligenciou e o Fundeb ainda não a financia plenamente. 


\section{REFERÊNCIAS}

ALVES, T. Desenvolvimento de um Modelo de Previsão de Custos para Planejamento de Sistemas Públicos de Educação Básica em Condições de Qualidade. 2012. 342f. Tese (Doutorado em Administração), Faculdade de Economia, Administração e Contabilidade, USP, São Paulo, 2012.

ALVE, T.; SILVA, R. M. da. Estratificação das oportunidades educacionais no Brasil: contextos e desafios para a oferta de ensino em condições de qualidade para todos. Educação \& Sociedade, Campinas, v.34, n. 124, p. 851-879, jul./set. 2013.

ARAÚJO, R. L. S. Perfil dos gastos educacionais nos municípios brasileiros. UNDIME: 2012. Disponível em: <http://undime.org.br/wp-content/uploads/2012/02/Relat\%C3\%B3riopesquisa-Perfil-dos-Gastos-Educacionais-Undime.pdf>. Acesso em 19 abr 2014.

ARELARO, L. R. G. O ensino fundamental no Brasil: avanços, perplexidades e tendências. Educação \& Sociedade. Campinas, v. 26, n. 92, p. 1039-1066, out. 2005.

BASSI, M. E.; FERMINO, P. P. O Atendimento à Educação Básica em Santa Catarina: repercussões do Fundef e do Fundeb na matrícula pública. 2011. Disponível em: <http:// nupefe.blogspot.com/2010/09/o-atendimento-educacao-basica-em-santa.html>. Acesso em: 20 fev. 2014.

BRASIL. Constituição (1988). Constituição da República Federativa do Brasil, 1988. Diário Oficial [da República Federativa do Brasil], Congresso Nacional, Brasília, DF, 5 out. 1988. n. 191-A. p. 1. Disponível em: <http://www.planalto.gov.br/ccivil_03/constituicao/ constituicao.htm>. Acesso em: 20 fev 2014.

Constituição (1988). Emenda Constitucional no 14, de 12 de setembro de 1996. Modifica os artigos. 34, 208, 211 e 212 da Constituição Federal e dá nova redação ao art. 60 do Ato das Disposições constitucionais Transitórias. 1996a. In: Legislação. Disponível em: <http://www.planalto.gov.br/ccivil_03/Constituicao/Emendas/Emc/emc14.htm>. Acesso em: 20 fev. 2014.

. Lei n. 9.394, de 20 de dezembro de 1996. Estabelece as diretrizes e bases da educação nacional. Diário Oficial [da República Federativa do Brasil], Brasília, DF, 23 dez. 1996b. Disponível em: <http://www.planalto.gov.br/ccivil_03/Leis/L9394.htm>. Acesso em 20 fev. 2014.

Lei n $n^{0}$ 9.424, de 24 de dezembro de 1996c. Dispõe sobre o Fundo de Manutenção e Desenvolvimento do Ensino Fundamental e de Valorização do Magistério, na forma prevista no art. $60, \int 7^{\circ}$, do Ato das Disposições Constitucionais Transitórias, e dá outras providências. In: Legislação. Disponível em: < http://www.planalto.gov.br/ccivil_03/leis/ 19424.htm> Acesso em: 20 fev. 2014.

. Lei n ${ }^{0} 10.172$, de 09 de janeiro de 2001. Aprova o Plano Nacional de Educação e dá outras providências. Diário Oficial [da] República Federativa do Brasil, Brasília, DF, 10 out. 2001. Disponível em: <http://www2.camara.leg.br/legin/fed/lei/2001/lei-10172-9-janeiro2001-359024-publicacaooriginal-1-pl.html>. Acesso em: 20 fev. 2014.

. Constituição (1988). Emenda Constitucional n 53, de 19 de dezembro de 2006. Dá nova redação aos artigos. $7^{\circ}, 23,30,206,208,211$ e 212 da Constituição Federal e ao art. 60 do Ato das Disposições Constitucionais Transitórias. 2006. In: Constituição da República Federativa do Brasil. Disponível em: < http://www.planalto.gov.br/ccivil_03/Constituicao/ Emendas/Emc/emc53.htm >. Acesso em: 20 fev. 2014.

Lei $n^{\circ}$ 11.494, de 20 de junho de 2007. Regulamenta o Fundo de Manutenção e Desenvolvimento da Educação Básica e de Valorização dos Profissionais da Educação 
- FUNDEB. 2007. Disponível em < http://www.planalto.gov.br/ccivil_03/_Ato20072010/2007/Lei/L11494.htm>. Acesso: 20 fev. 2014.

. Emenda Constitucional $n^{\circ}$ 59, de 11 de novembro de 2009. Disponível em: <http://www. planalto.gov.br/ccivil_03/constituicao/Emendas/Emc/emc59.htm>. Acesso em: 20 fev. 2014.

.ParecerCNE/CEBn 8 /2010, aprovadoem5 demaiode2010.Disponívelem: <http://portal. mec.gov.br $/$ index.php?option $=$ com_content\&view $=$ article\&id $=15074 \&$ Itemid $=866>$. Acesso em: 20 fev. 2014.

CAMPANHA NACIONAL PELO DIREITO À EDUCAÇÃO. Educação pública de qualidade: quanto custa esse direito?. 2. ed. São Paulo: Campanha Nacional pelo Direito à Educação, 2011. 82 p.

DAVIES, N. O Fundef e os equívocos na legislação e documentação oficial.

Cadernos de Pesquisa. Fundação Carlos Chagas, São Paulo, v. 113, p. 113-128, 2001.

FARENZENA, N. (Org.). Custos e condicõoes de qualidade da educação em escolas públicas: aportes de estudos regionais. Brasília INEP/MEC, 2005.

FARENZENA, N.; MACHADO, M. G. F. Um estudo do custo por aluno em escolas municipais brasileiras. Relatório de pesquisa, Porto alegre, 2006. Disponível em: <http://portal.cnm.org. br/sites/5700/5770/23062008_estudo_custo_aluno_2006.pdf>. Acesso em: 20 fev. 2014.

FINEDUCA. Por que a União deve complementar o CAQi no PNE? São Paulo, 2013. 8 p. (NOTA TÉCNICA 01/2013)

GOUVEIA, A. B. et al. Custo aluno/ano em escolas com condições de qualidade no Estado do Paraná. In: FARENZENA, N. (Org.). Custos e condições de qualidade da educação em escolas públicas: aportes de estudos regionais. Brasília INEP/MEC, 2005. p. 109-132.

LEITE, R. R. Fundeb: O que muda no financiamento da Educação Básica na Rede Municipal de Ensino de Anápolis, em 2007. Disponível em: <http://anaisdosimposio.fe.ufg.br/ pages/30805-paineis>. Acesso em: 4 de jul. 2013.

PINTO, J. M. de R. A política recente de fundos para o financiamento da educação e seus efeitos no pacto federativo. Educ. Soc., Campinas, v. 28, n. 100, p. 877- 898, 2007.

. Por que a união deve complementar o CAQi no PNE? (Nota Técnica 01/2013), Fineduca: 2013. Disponível em: http://www.redefinanciamento.ufpr.br/nota1_13.pdf. Acesso em: 20 fev. 2014.

SALES, L. C. et al. O custo aluno e as condições para um ensino de qualidade: o caso do Piauí. In: FARENZENA, N. (org). Custos e condições de qualidade da educação em escolas pública: aportes de estudos regionais. Brasília: INEP/MEC, 2005.

SALES, Luís Carlos; SILVA, Magna Jovita. O financiamento da educação pública municipal de Teresina: o custo-aluno/ano. Ensaio Avaliação Políticas Públicas Educacionais. Rio de Janeiro, v. 17 , n. 65, p. 695-718, out/dez, 2009.

- A movimentação das matrículas no Ensino Fundamental no estado do Piauí. Educação \& Realidade, Porto Alegre, v. 38, n. 4, p. 1041-1059, out./dez. 2013.

SILVA, M. J. G. de S. Custo direto de financiamento das escolas públicas municipais de TeresinaPiauí 2008. 143 f. Dissertação (Mestrado em Educação) - Programa de Pós-Graduação em Educação, Universidade Federal do Piauí. Teresina, 2008.

VERHINE, R. Levantamento do custo-aluno-ano em escolas de Educação Básica que oferecem condições de oferta para um ensino de qualidade - $2^{a}$ Etapa. (Salvador, Bahia), 2005. Disponível em: <http:// www.isp.ufba.br/INEP\%2024-05.pdf>. Acesso em 18 nov. 2013.

XAVIER, A. C. R.; MARQUES, A. E. S. Custo direto de funcionamento das escolas públicas de $1^{\circ}$ grau da região da região Sul. Brasília: Ministério da Educação, 1988. 


\section{NOTAS}

${ }^{1}$ O PNE foi finalmente sancionado em 25 de Junho de 2014, Lei 13.005.

${ }^{2}$ Anualmente, a União deve aplicar "nunca menos de dez por cento, e os Estados, o Distrito Federal e os Municípios nunca menos de vinte por cento da renda resultante dos impostos na manutenção e desenvolvimento do ensino" (CF/1946, Art. 169).

${ }^{3}$ O Fundo de Manutenção e Desenvolvimento do Ensino Fundamental e Valorização do Magistério foi criado pela Emenda Constitucional no 14/96, de 12/09/1996, e regulamentado pela Lei $n^{\circ} 9.424$, de 24 de dezembro de 1996. Em 1997, foi implantado apenas no estado do Pará. Em 1998, ampliou-se para todos os estados brasileiros.

${ }^{4}$ FPM e FPE significam respectivamente: Fundo de Participação dos Municípios e Fundo de Participação dos Estados.

${ }^{5}$ Conselho Nacional de Secretários de Educação.

${ }^{6}$ União Nacional dos Dirigentes Municipais de Educação.

${ }^{7}$ As matrículas das redes federal e estadual não foram apresentadas na Tabela 3, com o objetivo de deixar a tabela mais enxuta, uma vez que as matrículas dessas duas redes são desprezíveis em relação às matrículas das redes municipais e privadas.

${ }^{8}$ Ou seja, para cada 1000 matrículas na rede particular, em 2013, existiam 2.377 matrículas na rede municipal de Teresina.

${ }^{9}$ Ou seja, para cada 1000 matrículas na rede particular, em 2013, existiam em João Pessoa 819 matrículas e 807 em Aracaju.

${ }^{10}$ Neste estudo, não foi possível desagregar as despesas da Educação Infantil entre Creches e Pré-escolas.

${ }^{11}$ Os valores do CAQi por aluno/ano, em 2012, para Creches e Pré-escolas são respectivamente $\mathrm{R} \$ 8.288,28$ e $\mathrm{R} \$ 4.171,77$. O uso desses valores reforçaria ainda mais os argumentos utilizados nas Considerações Finais deste artigo, sobre a insuficiência de recursos para custear a Educação Infantil.

${ }^{12}$ Esses valores foram retirados da Nota Técnica da No 001/2013 da Associação Nacional de Pesquisa em Financiamento da Educação (FINEDUCA), a qual estima os valores de complementação da União ao Fundeb, tomando como referência o CAQi (Custo Aluno-Qualidade Inicial), compreendido como materialização do conceito de padrão mínimo de qualidade do ensino, conforme o Parecer da Câmara de Educação Básica do Conselho Nacional de Educação (CEB/CNE) no 8/2010. A nota foi elaborada pelo Prof. Dr. José Marcelino Rezende Pinto (USP/Ribeirão Preto e presidente da Fineduca), com colaboração de Daniel Cara (mestre em Ciência Política/USP) e Luiz Araújo (doutor em educação/USP e vice-presidente da Fineduca).

Recebido: 01/10/2014

Aprovado: 19/02/2015

Contato:

Luís Carlos Sales

Rua Coelho de Resende, 2247

Teresina | PI|Brasil

CEP 64.002-470 
